\title{
Integration of heat pump and gas turbine combined cycle: market and climatic conditions for power plant flexibility enhancement
}

\author{
Andrea Giugno ${ }^{1}$, Alessandro Sorce ${ }^{1}$, Alessandra $\mathrm{Cuneo}^{2 *}$ and Stefano Barberis ${ }^{2}$ \\ ${ }^{1}$ Thermochemical Power Group, University of Genoa, Via Montallegro 1, 16145 Genoa, Italy \\ ${ }^{2}$ RINA Consulting, Via San Nazaro 19, 16145, Genoa, Italy
}

\begin{abstract}
The increasing share of electricity produced from renewable energy sources (RES), with the consequent strong penetration in the current energy network, is causing a growing need of balancing power to compensate power supply from such fluctuating sources. For these reasons, nowadays the power plants are requested to improve their operational flexibility, together with their global efficiency in part-load operation, for ancillary services and to sustain the grid operability. A possible solution for flexibility enhancement is characterized by a highly efficient heat pump integrated in a conventional natural gas combined cycle (CC). Such concept can be applied both to power oriented combined cycle (POCC), to modify the compressor intake temperature with a consequent increase or decrease of the power production, and both to cogeneration $\mathrm{CC}$ in association with District Heating Network (DHN). In this work, a statistical analysis of climatic data and their correlations with energy market condition will be performed considering Italian context, to understand which the more suitable conditions for such integrated system are. The analysis will be performed on seasonal and daily basis. The final aim of this work is to identify how such integrated system can be operated at its best in the different Italian markets and climatic frames.
\end{abstract}

\section{Introduction}

In the last years, a consistent evolution of combined cycle performance was shown, mainly commanded by the market. The intermittent renewable capacity has increased dramatically in the last 10 years, due also to the EU target [1], having a major impact on markets. The growth of renewable energy sources is, of course, highly beneficial to the environment but introduces intermittency into grid management. This rapid growth in variable generation is driving the need for a more flexible power system and for a research and development strategy to help achieve that.

In such new energy scenario, the combined cycle gas turbines (CCGT) have to change the way they operate: from a baseload to backup [2]. CCGT must now respond rapidly to variations due to renewable supply and demand, requiring a more flexible cyclic pattern of use [3]. Making conventional power plants more flexible can be a key strategy to integrate large shares of renewables more effectively in power systems $[1,2]$. 
An innovative concept based on the coupling of a fast-cycling highly efficient Heat Pump (HP) with the CCGTs is here proposed [4], within the framework of an H2020 EU project called PUMP-HEAT [5]. This possible solution for flexibility enhancement is characterized by a highly efficient heat pump integrated in a CCGT, featuring cold/warm thermal storage and advanced control. Such concept can be applied both to power oriented combined cycle (POCC), to modify the compressor intake temperature with a consequent increase or decrease of the power production, and both to cogeneration CCGT in association with District Heating Network (DHN). In this work, a statistical analysis of climatic data and their correlations with energy market condition will be performed considering the Italian market scenario, to understand which is the more suitable conditions for such integrated systems.

The final aim is to identify how PUMP HEAT concept can be operated and the influences that different Italian price zones and climatic conditions can have on its profitability. The Power Oriented (PO) combined cycle configuration is taken into consideration during this analysis, with a particular attention on the continuous cooling mode (Figure 1). Such operational mode allows to modify the compressor intake temperature thanks to the cold energy produced by the heat pump. The cooling of the inlet temperature increases the maximum power output of the CC (about 10\%) during peak hours, with also an increase of the yearly efficiency and production.

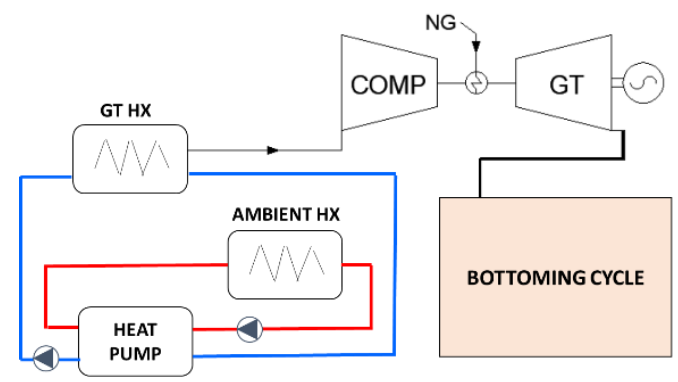

Figure 1. Power oriented HP-CC concept scheme working in continuous cooling

The heat pump produces cold energy using ambient air through a dedicate heat exchanger (ambient HX in Figure 1) as energy source. The performances of the heat pump in terms of $\mathrm{COP}$ and the temperature that can be reached at the compressor inlet are dependent on the ambient temperature. However, to consistently evaluate the HP performance, both ambient temperature and humidity were considered. In addition, in this work, it was always considered to work at the maximum load of the heat pump, not considering off-design conditions. In fact, from the optimization analysis performed during the PUMP-HEAT project, it resulted that this would be the condition that maximizes the economic benefit. However, a minimum threshold value of $5^{\circ} \mathrm{C}$ was set at the compressor inlet to avoid the risk of ice formation. The CCGT model was validated in previous work with respect to the effect of ambient temperature. the effect of GT intake humidity on the CCGT overall performance was neglected as conservative assumption as explained in [4].

\section{Italian electricity scenario}

As part of the new National Energy Strategy, Italy set itself the goal of the phase out of coal by 2025 , aiming to expand the share of renewable energy in final energy consumption to $28 \%$ by 2030 [6]. The Italian wholesale electricity market started to operate as an Exchange in 2005 with the liberalization of the demand side bidding. In 2017 gross national production amounting to $295.8 \mathrm{TWh}$ was satisfied for $70.8 \%$ by thermoelectric production $(+5.0 \%$ 
compared to 2016 ), for $12.8 \%$ by hydroelectric production and for the remaining $16.3 \%$ by geothermal, wind and photovoltaic sources (with an increase of $10.3 \%$ respect to the previous year) [7]. The Italian electricity market operates in three different periods: (i) daily market (MGP), which trades most of the electricity purchase and sale transactions (ii) intra-day market (MI) consisting of seven sessions which allow market participants to modify the programs defined in the daily market by sending additional sales or purchase offers and (iii) the market for continuous trading of daily products (MPEG). The electricity system is divided into zones classified into geographical zones, national virtual zones and foreign virtual zones. The geographical zones represent a part of the national network; there are currently six active zones: Northern Italy (NORD), Central-Northern Italy (CNOR), Central-Southern Italy (CSUD), Southern Italy (SUD), Sicily (SICI) and Sardinia (SARD). The MGP market is a marginal market in which the price and volume of each hour are established from the point of equilibrium between supply and demand. Matched purchase offers referring to units of consumption belonging to Italian geographical areas are valued at the single national price (PUN). The PUN price is equal to the average of the prices of the zones, by zonal consumption and represents the purchase price for end customers. In the last years, due to the increase of RES and to a reduction of the natural gas price, the PUN in all the zones has decreased consistently (Figure 2). The Sicily zone, however, seems to be the most interesting one where to study continuous cooling concept, with an average zonal price always higher respect to the national PUN $(+13 \%$ in 2017$)$. The volatility of minimum and maximum prices of this region is much higher than in the rest of Italy and the other macro regions [8]
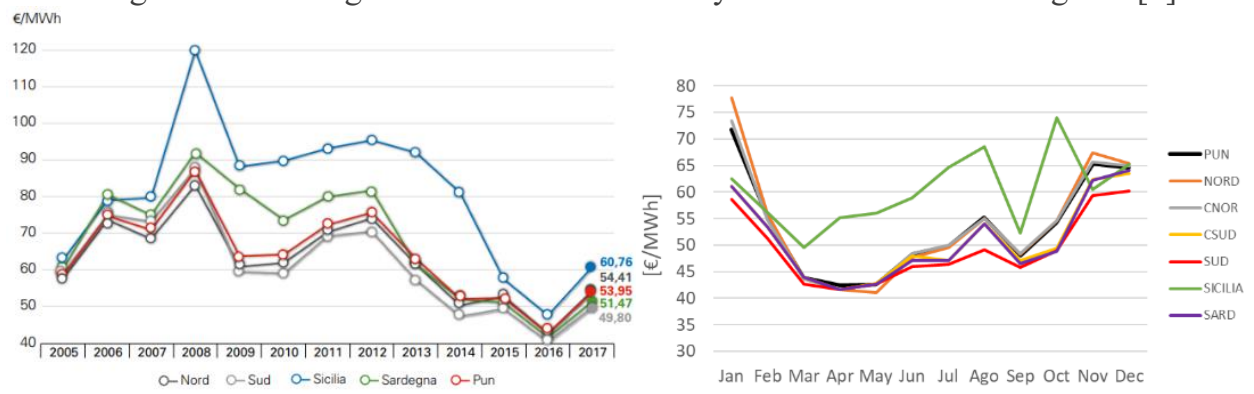

Figure 2. Annual average zonal price on MGP (left) and monthly average zonal price in 2017 (right) [9]

In this market scenario, the use of a heat pump (HP) to decrease the temperature at the compressor inlet do not depend only on the electricity price but it is also related to the ambient temperature. In the following sections, a statistical analysis to correlate the price and the ambient temperature is performed, as well as a first order economic analysis of the proposed integrated system $(\mathrm{CCGT}+\mathrm{HP})$.

\section{Statistical Analysis}

The distribution of the electricity price plays a major role over the profitability of CCGT power plants, presenting an average production cost, i.e. the Cost of Electricity, COE, aligned with the average value of the PUN. The overall profitability of the proposed power augmentation application, continuous cooling by a HP, can be related to the electricity peak absolute price and to the temperature and price peak coupling. In a broader approach, considering the use of a Thermal Energy Storage (TES) to accumulate the cold energy during the off-peak periods, also the respective temperature and price minima must be considered. The daily temperature and price variation can increase the benefit related to TES installation, in particular when electrical price and temperatures maxima or minima occurs at the same 
time. Also the width of the positive and negative peaks, i.e how many hours can be accounted as "high range" and "low range" can be related to the system profitability. Such extreme conditions were defined with respect to the daily variation $\Delta$ daily $_{\mathrm{x}}=\max (x)-\min (x)$, as:

$$
\begin{gathered}
\text { High range }_{x}=\left[\max (x)-\frac{\Delta \text { daily }_{\mathrm{x}}}{20}, \max (x)\right] \\
\text { Low range }_{x}=\left[\min (x), \min (x)+\frac{\Delta \text { daily }_{\mathrm{x}}}{20}\right]
\end{gathered}
$$

This definition allows preserving at least $90 \%$ of the $\Delta$ daily $_{x}$ between high and low range of the variable, as depicted in Figure 3 for the temperature for a representative day. The points with the $\mathrm{x}$ markers and $\boldsymbol{\nabla}$ are respectively for high and low range and are counted to evaluated the peak extension, in this case respectively 4 and 5 hours.

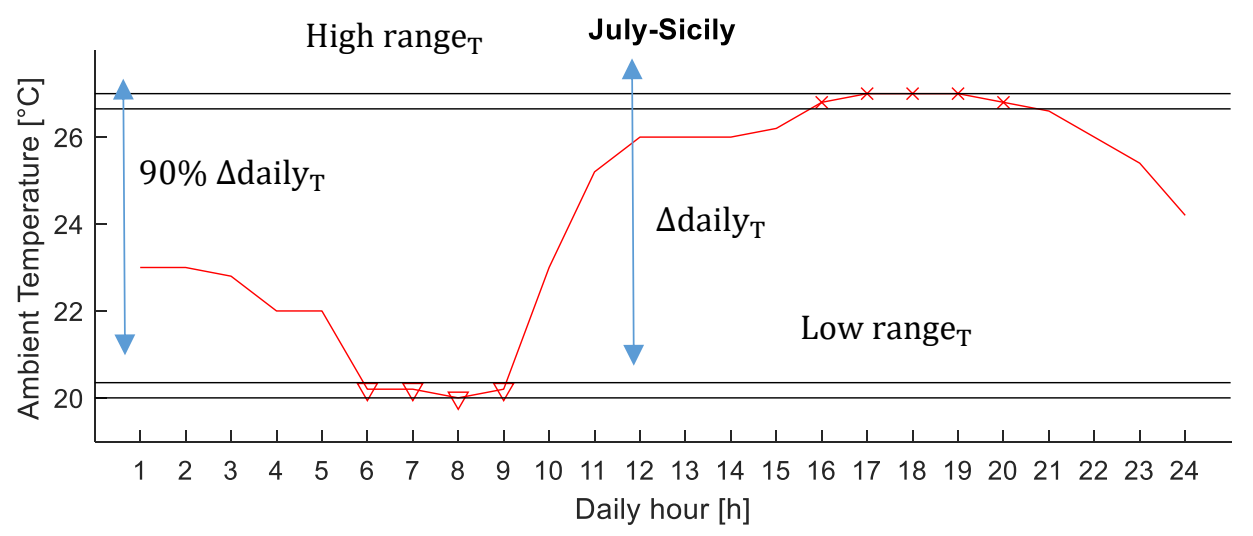

Figure 3. Example of the peak analysis: red line, ambient temperature $\left[{ }^{\circ} \mathrm{C} ; x\right.$ high range value; $\nabla$ low range value

The statistical analysis considers six price zones and six geographical location, as reported in Table 1, while price data were acquired by the Italian Gestore del Mercato Elettrico [9].

Table 1. Meteorological data measurement point [10]

\begin{tabular}{|l|c|c|c|}
\hline \multicolumn{1}{|c|}{ Zones } & Location & Position [N lat., E long.] & Altitude [m] \\
\hline North & Turin / Bric della Croce (airport) & $45^{\circ} 02^{\prime}, 07^{\circ} 44^{\prime}$ & 709 \\
\hline CNorth & Ancona / Falconara (airport) & $43^{\circ} 37^{\prime}, 13^{\circ} 22^{\prime}$ & 12 \\
\hline CSouth & Rome / Fiumicino (airport) & $41^{\circ} 48^{\prime}, 12^{\circ} 14^{\prime}$ & 2 \\
\hline South & Bari & $41^{\circ} 8.17^{\prime}, 16^{\circ} 45.78^{\prime}$ & 42 \\
\hline Sard & Capo Caccia & $40^{\circ} 34^{\prime}, 08^{\circ} 10^{\prime}$ & 200 \\
\hline Sici & Trapani-Birgi (airport) & $37^{\circ} 54.7^{\prime}, 12^{\circ} 29.6^{\prime}$ & 7 \\
\hline
\end{tabular}

Figure 4 represents the average maximum and the minimum value of the electrical price within the six Italian zones. The size of the marker is proportional to the number of hours in the high and low range (i.e. the peak extension). The distance between the two marker centres, in the same month, is equal to the average $\Delta$ daily $_{\mathrm{x}}$. The maximum price values are registered in the North and in Center North during the first two months of the year, while the South presents always lower prices. This could be related to the high number of CCGT 
production sites and wind farm installed in a region with a relative low power demand. It can be noticed that the prices in all the zones experience a reduction until April (loosing up to 54 $€ / \mathrm{MWh}$ ) and then a recovery. The maximum price of Sicily shows a less pronounced reduction in price until April $(\mathrm{Pmax}=85.6 € / \mathrm{MWh})$ and then remains above $90 € / \mathrm{MWh}$. In this zone, also the width of the peak price is different respect to the other zones in Italy. In Sicily, the average of the high range is up to 6h/day during the hot season and the yearly average is around 4 hours versus the average of $1.66 \mathrm{~h} /$ day of the other zones. Looking at the daily price variation, for the first five zones the changes appear to be related to a seasonal trend with a strong reduction during the hot months.
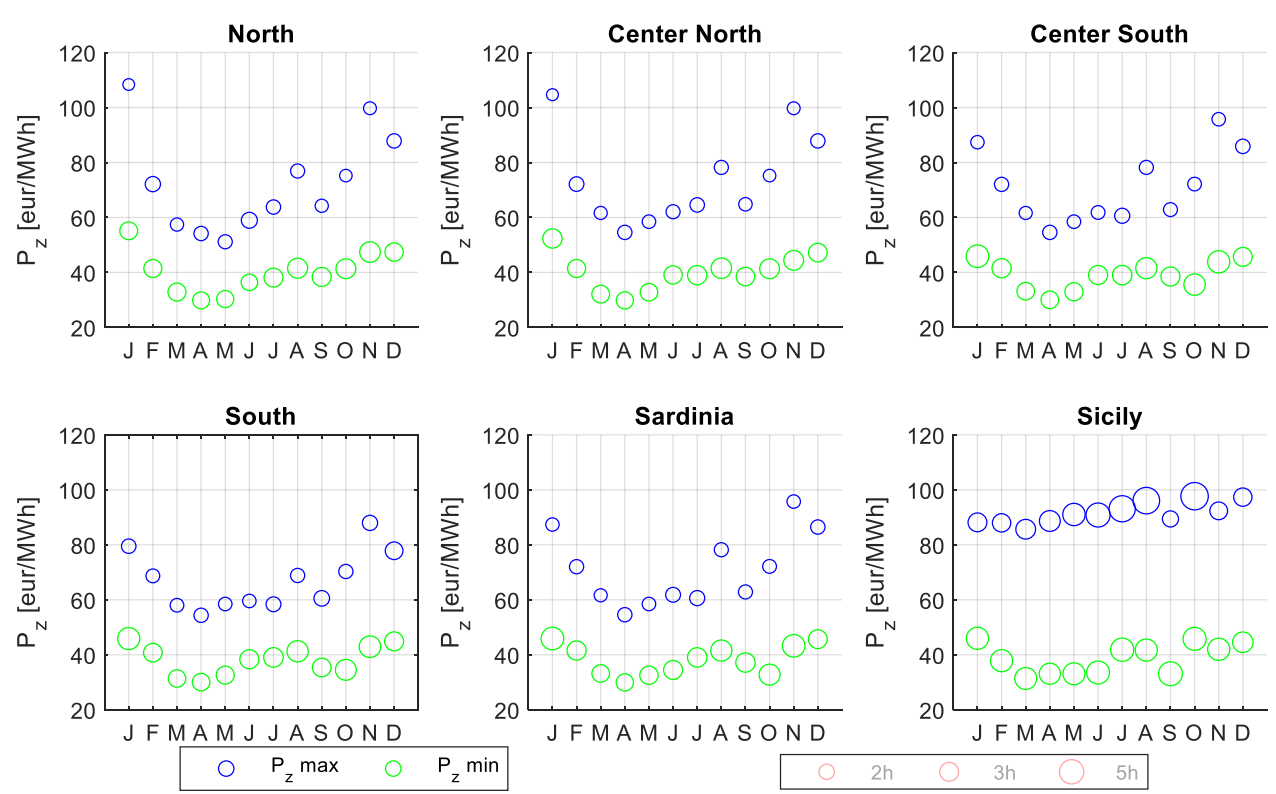

Figure 4. Monthly averaged max daily peak and min off-peak zonal price, the size of the marker is proportional to the peak extension hours.

The daily ambient temperature variation, which is evaluated as the difference between the maximum and the minimum temperature value in the same month, presented in Table 2, shows a trend that increases during summer due to the increase of the solar radiance, except for the South location. This is beneficial to the TES application, as they are usually employed during the hot months. The monthly average maximum and minimum temperatures, not reported here, as expected, increase during the summer period.

Table 2. Monthly average daily variation of ambient Temperature [K]

\begin{tabular}{|l|c|c|c|c|c|c|c|c|c|c|c|c|}
\hline Zones & Jan & Feb & Mar & Apr & May & Jun & Jul & Aug & Sep & Oct & Nov & Dec \\
\hline North & 4.0 & 3.5 & 5.5 & 6.8 & 7.0 & 7.0 & 6.7 & 6.3 & 5.8 & 4.8 & 3.3 & 3.5 \\
\hline CNorth & 6.7 & 7.7 & 10.2 & 10.1 & 9.6 & 10.3 & 10.3 & 10.3 & 8.5 & 9.8 & 8.0 & 8.5 \\
\hline CSouth & 9.0 & 8.4 & 10.2 & 10.7 & 10.8 & 9.7 & 10.5 & 11.1 & 8.9 & 10.7 & 8.9 & 9.4 \\
\hline South & 5.0 & 6.1 & 6.0 & 6.3 & 5.6 & 5.3 & 5.3 & 6.0 & 6.9 & 6.4 & 6.5 & 5.7 \\
\hline Sard & 4.5 & 4.5 & 4.6 & 4.9 & 5.5 & 5.4 & 6.0 & 6.5 & 4.4 & 4.3 & 3.5 & 3.1 \\
\hline Sici & 7.1 & 7.7 & 9.0 & 9.2 & 9.0 & 10.5 & 9.2 & 10.0 & 7.4 & 7.6 & 6.8 & 6.7 \\
\hline
\end{tabular}




\subsection{Peak coupling of the ambient temperature and the electrical price}

Under the proposed application perspective, another important effect that increases the benefit of the inlet cooling system, is the location of the price and temperature peak within the daytime.
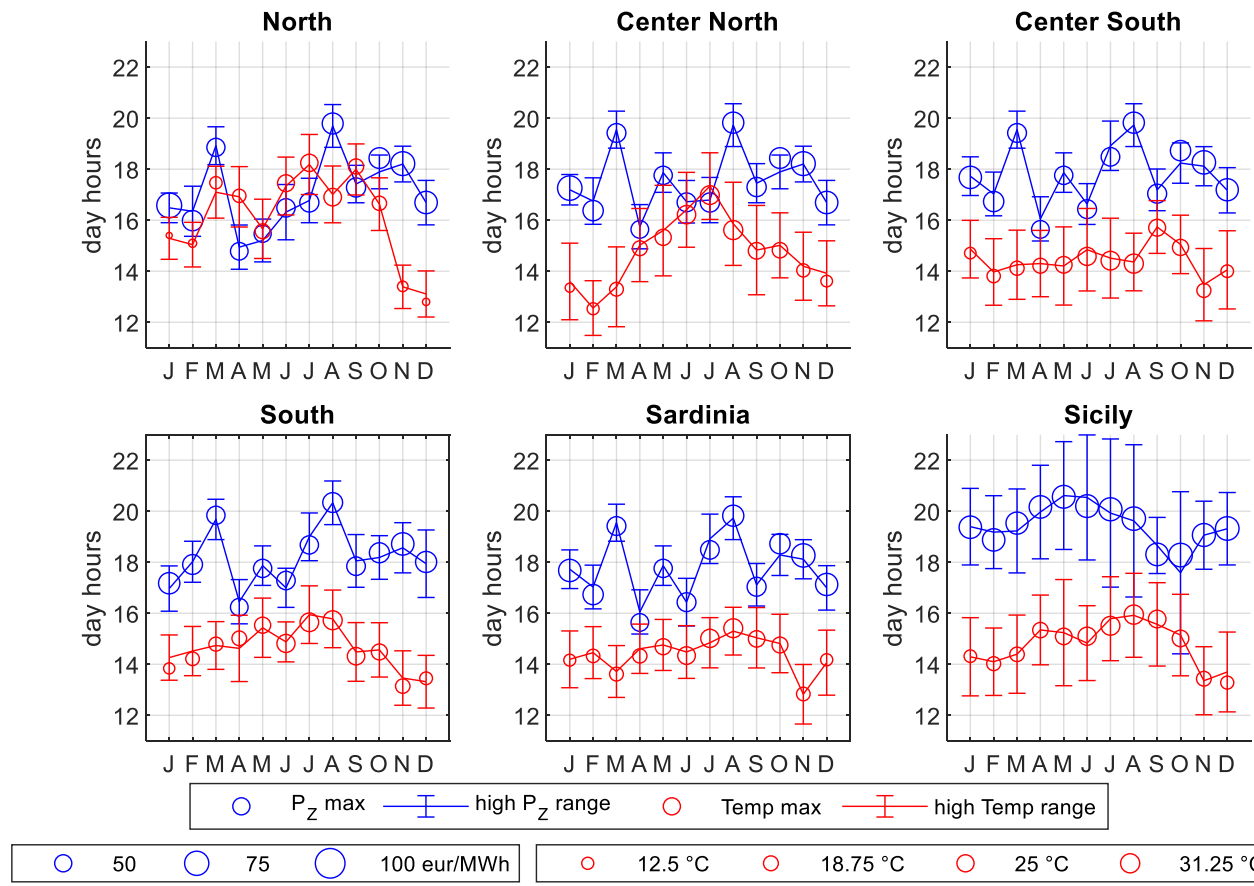

JFMAM J JASOND

high Temp range

Figure 5. Monthly averaged daily peak positions: blue circle Zonal Electricity Price peak (max) value (size proportional to price), blue lines price peak extension; red circle ambient temperature peak (max) value (size proportional to temperature), red lines temperature peak extension

It can be noticed that the maximum daily temperature is registered around the first two hours after noon, apart from the northern locations in which the peak is delayed up to $5 \mathrm{pm}$. The duration of the peak is intense in Sicily (a year average of $3.1 \mathrm{~h} /$ day) and in Center-North locations $(2.89 \mathrm{~h} /$ day $)$, with a slightly higher value in the summer months.

The price peaks occur later in the day moving from North to South, from $5 \mathrm{pm}$ in the North zone and $5.30 \mathrm{pm}$ in the Center-North, to $6 \mathrm{pm}$ in the South. The Sicily zone differs also for this parameter, with an average price peak that occurs at $7.25 \mathrm{pm}$. However, the price enters the high range at about $6 \mathrm{pm}$, with a longer persistence in the summer months up to $11 \mathrm{pm}$. The temperature and price peaks appear to be separated in time of 1-2 hours, except for the northern regions in which there is a partial overlap.

\section{Economic analysis}

The continuous inlet cooling system performance were calculated taking into account five different heat-pump (HP) sizes [1, 3, 4, 5 and 7.5 MWe] and the six geographical zones described in the previous section. Such locations were used as possible sites for the 
installation of the CC+HP layout to perform the continuous cooling of the turbine intake to enhance the performance of the system and so evaluate the earnings that such system would guarantee. The HP are considered to operate to reach a target inlet temperature of the GT intake of $5^{\circ} \mathrm{C}$, which has been identified as the minimum reachable temperature without the ice formation risk.

The CC net power and efficiency dependence on the inlet GT temperature was obtained from the Gate Cycle calculation presented in [4] and so the earnings that such system would produce over the year, taking 2017 as reference, were computed as:

$$
\begin{aligned}
\text { Earnings }= & \sum_{i=1}^{8760} E_{\text {prod }, i} \cdot\left(P_{Z, i}-\left(C_{f i x}+\frac{C_{\text {gas }}}{\eta_{C C}}\right)\right) ; \\
& \text { if } P_{Z}>C_{f i x}+\frac{C_{\text {gas }}}{\eta_{C C}}[€]
\end{aligned}
$$

Where $E_{\text {prod,i } i}$ is the energy produced by the CC at the i-th hour as function of the temperature, $\mathrm{Pz}$ is the zonal price, Cfix and Cgas represent the fixed costs of the plant and the gas cost based on $[9,11]$, and $\eta_{C C}$ is the CC efficiency as function of the temperature. To estimate the cooling potential of a given climatic profile, the concept of Continuous Equivalent Cooling Degree Hours (ECDH) is introduced, based on [12], and evaluated as:

$$
E C D H=\sum_{i=1}^{8760}\left(T_{a m b, i}-T_{r e f}\right) \quad \text { if } T_{a m b, i}>T_{r e f}
$$

Where $T_{\text {ref }}$ for this study is set to $5^{\circ} \mathrm{C}$ for the reasons explained before. From Figure $6 \mathrm{~b}$ it can be observed that the $\Delta$ Earnings, calculated as percentage variation from the earnings that the same $\mathrm{CC}$ would guarantee in ambient conditions, tend to increase while moving from North to South of Italy, due to the temperature increase over the year which would allow a higher exploitation of the continuous cooling system proposed. However, it can also be highlighted that the South area (SUD) presents high ECDH, but low percentage earnings compared to the other areas considered, due to the lower Pz.

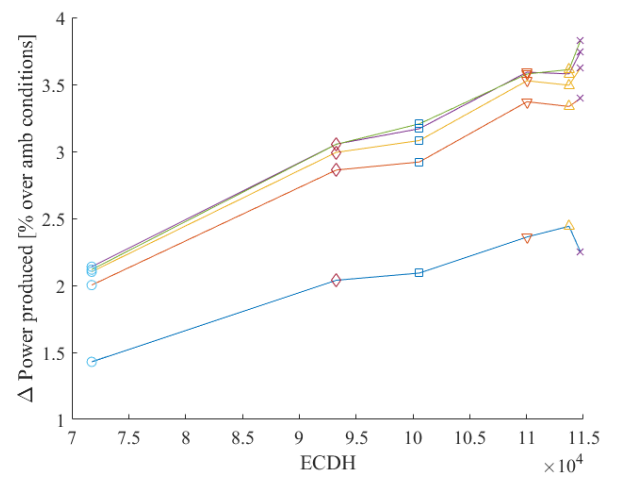

(a)

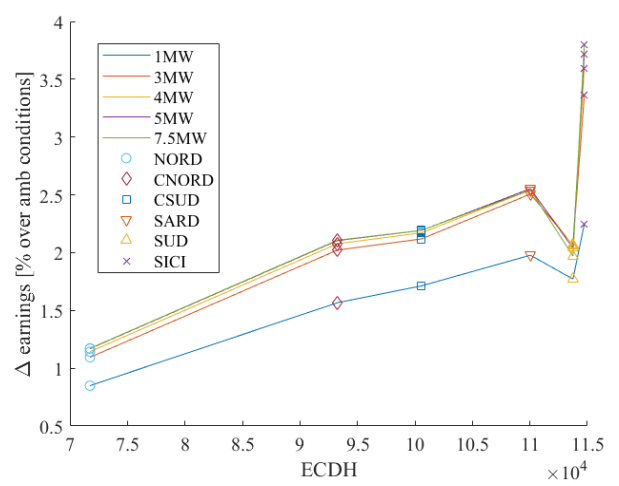

(b)

Figure 6 : (a) percentage power production and (b) percentage earnings over ambient conditions for five different HP sizes and six different areas of Italy

This trend becomes more evident increasing the HP size over $1 \mathrm{MW}$, as $\Delta$ Earnings becomes lower than all the other areas apart from the North (NORD) one. This effect is 
mostly related to the PUN of the South being lower than the national mean and other areas considered, which does not allow a good exploitation of the power produced (Figure 6a).

The high PUN of Sicily allows to benefit more from this layout not only thanks to the higher average temperatures, resulting in a maximum $\Delta$ Earnings of about $4 \%$ using a $7.5 \mathrm{MW}$ HP. On the other hand, from Figure 6a it can be observed that the percentage power variation considering Sicily and a 1MW HP is lower than SUD and SARD. This is due to the fact that temperatures in Sicily are particularly high and then a 1MW HP would not be able to reach the target temperature of $5^{\circ} \mathrm{C}$, resulting in a power augmentation lower than the actual possibility. Indeed, also the worst result, obtained from using a 1MW HP in Northern Italy, would guarantee an increase of earnings of about $0.8 \%$ for the year considered.

Moreover, it can be highlighted that the lines corresponding to the HPs of 5 and $7.5 \mathrm{MW}$ become very close in terms of earnings, suggesting that when the investment cost comes in place within the calculations, it would probably be more profitable to buy a 5MW HP which would result in lower capital and installation costs.

\section{Conclusions}

The statistical analysis of climatic data and their correlations with energy market condition was performed considering Italian context for six different electricity market zones. The analysis was also carried out on monthly and daily basis introducing a technique to identify the range of extreme values of the daily distribution on the base of the daily price variation. It was highlighted how the daily price variation reduces during the hot months, while the temperature daily variation increases, as expected, due to the increase in solar radiant energy during the summer time. Finally, Sicily market zone, shows a strongly different behaviour, characterized by high and persistent maximum prices, with a yearly average of $20 € / \mathrm{MWh}$ over the other zonal prices.

Focusing on the Italian market, the profitability of a continuous inlet cooling system becomes more attractive moving from north to south due to the increase of the average temperatures. On the other side, the South electricity price, the lowest in the peninsula, has a low profitability compared to the meteorological potential. The gain in power of the proposed system is proportional to the climatic condition summarized by the Continuous Equivalent Cooling Degree Hours, plus the effect of the zonal price. Under the actual condition the Sicily market has the largest potential, maximizing both the temperature and electrical price effect.

This project has received funding from the European Union's Horizon 2020 research and innovation programme under Grant Agreement No 764706, PUMP-HEAT. (http://www.pumpheat.eu).

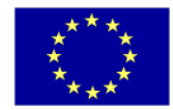

\section{References}

[1] European Parliament, 2018, Directive (EU) 2018/2001 of the European Parliament and of the Council of 11 December 2018 on the Promotion of the Use of Energy from Renewable Sources.

[2] Agora Energiewende, 2017, Flexibility in Thermal Power Plants.

[3] Prina, M. G., Garegnani, G., Moser, D., Oberegger, U. F., Vaccaro, R., Sparber, W., Gazzani, M., and Manzolini, G., 2015, "Economic and Environmental Impact of Photovoltaic and Wind Energy High Penetration towards the Achievement of the Italian 2020-20 Targets," 2015 10th International Conference on Ecological Vehicles and Renewable Energies, EVER 2015.

[4] Sorce, A., Giugno, A., Marino, D., Piola, S., and Guedez, R., 2019, “Analysis of a 
Combined Cycle Exploiting Inlet Conditioning Technologies for Power Modulation," Proceedings of ASME Turbo Expo 2019: Turbomachinery Technical Conference and Exposition GT2019.

[5] "Pump-Heat" [Online]. Available: www.pumpheat.eu. [Accessed: 30-Apr-2019].

[6] Ministero dello Sviluppo Economico, Proposta Di Piano Nazionale Integrato per l'Energia Ed Il Clima.

[7] TERNA, 2018, Dati Statistici Sull'energia Elettrica in Italia.

[8] Antonelli, M., Desideri, U., and Franco, A., 2018, "Effects of Large Scale

Penetration of Renewables: The Italian Case in the Years 2008-2015," Renew. Sustain.

Energy Rev.

[9] Gestore Mercati Energetici, "Dati Storici Mercati Gas" [Online]. Available: http://www.mercatoelettrico.org/It/download/DatiStoriciGas.aspx. [Accessed: 07-Apr2019].

[10] "Weather in the World" [Online]. Available: https://rp5.ru/Weather_in_the_world. [Accessed: 30-Apr-2019].

[11] Ricerca sul Sistema Energetico - RSE Spa, 2017, Energia Elettrica, Anatomia Dei Costi.

[12] Ancona, M. A., Bianchi, M., Melino, F., and Peretto, A., 2015, "Power Augmentation Technologies: Part II — Thermo-Economic Analysis." 